Recebido: $27 / 08 / 2019$

Aprovado: 04/09/2019

DOI: $10.26512 / e m t e m p o s . v 1 i 34.28168$

\title{
Estevão de Rezende Martins e a ciência da mediação
}

\author{
Arthur Alfaix Assis ${ }^{1}$
}

Resumo: Esta contribuição aborda a trajetória acadêmica de Estevão de Rezende Martins, um dos mais importantes humanistas hoje em atuação no espaço universitário brasileiro. São arroladas várias das suas realizações profissionais (na universidade e em outras instituições) e analisados os seus principais escritos - os quais se concentram em temas como a história das ideias na era do Iluminismo, a teoria e a metodologia da história, o ensino de história, a história das instituições parlamentares e o processo da unificação europeia. Alguns dos objetivos são colocar em relevo a vocação interdisciplinar subjacente às pesquisas e às práticas profissionais de Estevão Martins, e ilustrar como tal orientação o tornou apto para desempenhar um (imprescindível e cada vez mais negligenciado) papel de mediador entre diferentes domínios e tradições das ciências humanas. Para além dos propósitos informativo e analítico, o texto também guarda um forte caráter comemorativo, pois remonta ao discurso lido em dezembro de 2018 na cerimônia de outorga do título de professor emérito pela Universidade de Brasília.

Abstract: This contribution addresses the academic path of Estevão de Rezende Martins, one of today's leading humanists in the Brazilian university landscape. It

\footnotetext{
${ }^{1}$ Professor associado do Departamento de História e do Programa de Pós-Graduação em História da Universidade de Brasília. Doutor pela Universidade de Witten/Herdecke, Alemanha. Contato: arthurassis@ unb.br
} 
catalogues several of his scholarly and professional accomplishments, and analyses his most important writings - which concentrate on subjects such as history of ideas in the Age of Enlightenment, theory and methodology of history, history education, history of parliamentary institutions, and the process of European unification. Some of the goals are to highlight the interdisciplinary orientation implied in Martins' intellectual projects and practices, and to illustrate how that made him especially fit for the (indispensable though increasingly neglected) role of a mediator between different fields and traditions within the human sciences. In addition to its informative and analytic purposes the text also fulfils a commemorative function, since it is based on the speech delivered in December 2018 on the emeritus professor award ceremony organized by the University of Brasília.

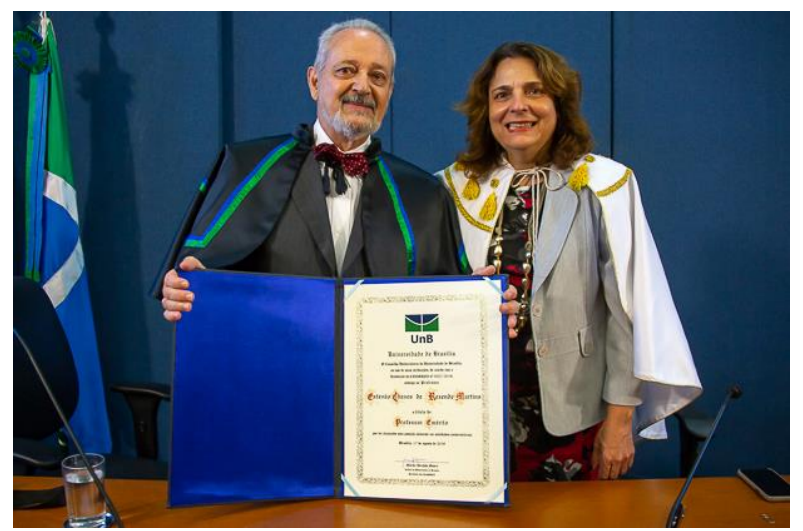

(Estevão de Rezende Martins recebe da Reitora da Universidade Brasília, a Profa. Márcia Abrahão Moura, o diploma de Professor Emérito. Foto: Raquel Aviani/Secom UnB, 11.12.2018)

O presente texto tem por base o discurso que proferi por ocasião da outorga do título de professor emérito a Estevão de Rezende Martins pela Universidade de Brasília, em 11 de dezembro de 2018. Foi posteriormente revisto, ampliado, e adaptado para a publicação no presente formato. $O$ saldo final é, como não poderia deixar de ser, uma laudatio que rememora as principais realizações do homenageado, embora temperada por momentos mais analíticos em que são examinadas ideias e argumentos centrais presentes nos textos dele.

Recapitular e analisar uma trajetória acadêmica na forma de um discurso como o que segue abaixo é obviamente uma tarefa não só de história, mas também (se exagerarmos um pouco na oposição) de memória. Mas a incidência do que vai ser rememorado, comemorado e explicado a seguir não se limita à esfera biográfica. Estevão Martins atua há mais de quarenta anos no Programa de PósGraduação em História da UnB, e a sua trajetória profissional confunde-se em muitos pontos com a do próprio programa. Como em nenhum outro lugar é no PPGHIS-UnB que ele tem concorrido, na condição de docente e orientador, para a formação intelectual de novas gerações de acadêmicos. Foi

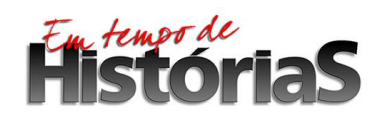


também no âmbito desse programa que eu próprio, à época do meu mestrado, estive sob a supervisão dele ï e devo dizer que essa experiência foi por diversas razões decisiva para o meu próprio caminho intelectual, profissional, e também pessoal. Disso tudo resultam significados especiais que se intensificam com a publicação do texto por um veículo com sede na UnB, e que é editado justamente pelos nossos mestrandos e doutorandos em História.

De acordo com o Art. 66 do seu Estatuto, a Universidade de Brasília pode atribuir título de Professor Emérito a docente aposentado, que tenha alcançado uma posição eminente em atividades universitárias. A linguagem contida com que esses documentos normativos costumam ser escritos não nos deve, entretanto, enganar acerca do sentido vivo por detrás dessa relativamente fria previsão estatutária. O pensamento que lhe subjaz é o de que uma universidade como a nossa não se deve limitar a produzir e repartir conhecimentos; deve também, de vez em quando, comemorar os melhores resultados alcançados nesses processos.

Senhoras e senhores, é precisamente para uma dessas comemorações que aqui estamos hoje. Com ela, não só fazemos justiça às realizações de um colega e amigo; celebramos também, ao mesmo tempo, a nossa própria universidade como um lugar que abriga e fomenta trajetórias humanas e produções intelectuais extraordinárias. Por isso, uma circunstância como a de hoje é, curiosamente, tão importante para a própria instituição que promove a homenagem do que para a pessoa que merecidamente a recebe. Afinal de contas, pessoas extraordinárias, capazes de ações e produtos invulgares, são a base de tudo o que é vivo na universidade.

A trajetória do nosso homenageado de hoje está profundamente marcada por esse sentido de elevação intelectual que se identifica com as mais importantes finalidades da vida universitária. Nascido em 1947, no Rio de Janeiro, Estevão Chaves de Rezende Martins cursou o tradicional Colégio Santo Inácio. Concluído o curso secundário, ingressou em 1967 no curso de filosofia da Faculdade de Ciências e Letras Nossa Senhora Medianeira, então mantida pela Companhia de Jesus nos arredores da cidade de São Paulo. Considerando dedicar-se ao sacerdócio, mudou-se para a Áustria em 1971, vinculando-se à Universidade de Innsbruck, na qual frequentou cursos de teologia e filosofia. Em 1973 transferiu-se para a Universidade de Munique, onde estudou com professores como o historiador Thomas Nipperdey e o filósofo Hans-Michael Baumgartner, e onde em 1976 concluiu o seu doutoramento, sob a orientação do eminente historiador da filosofia Wolfgang Röd.

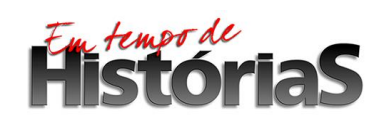


Estevão de Rezende Martins faz parte do corpo docente da Universidade de Brasília desde março de 1977, quando foi contratado para atuar em disciplinas de teoria e metodologia, especialmente no então jovem curso de mestrado em História. Figura decisiva para a sua fixação no Brasil Central foi o filósofo Nelson Gonçalves Gomes, com quem havia convivido em Munique e que já se encontrava na UnB desde o primeiro semestre de 1976 (Martins 2010, 395-396). No Instituto de Ciências Humanas da nossa universidade, Estevão Martins esteve vinculado aos diferentes departamentos que agruparam as áreas de História e Filosofia. Em 1986, quando cada área se emancipou num departamento próprio, fixou-se no Departamento de Filosofia. Transferiu-se depois, em 1995, para o Departamento de História, atendendo a um convite dos Profs. José Flávio Sombra Saraiva e Amado Luiz Cervo. Quando, em 2002, esses e outros colegas transferiram a linha de pesquisa em que atuavam para a pósgraduação em Relações Internacionais, do então recém-criado IREL, Estevão Martins acompanhou-os (Saraiva 2017, 318). Mas optou por permanecer lotado no Departamento de História, e por continuar atuando, paralelamente, no Programa de Pós-Graduação em História. No fim das contas, esse programa é a instância da UnB a que sempre se manteve vinculado.

Foi o diretor do Instituto de Ciências Humanas entre 2007 e 2011, ou seja, num período não exatamente tranquilo do passado da $\mathrm{UnB}$, em que as suas habilidades políticas e administrativas foram bastante demandadas. Em 2008, foi aprovado em concurso para professor titular da área de Teoria da História, cargo do qual se aposentou em 13 de junho de 2017. Permanece, entretanto, ligado ao Programa de Pós-Graduação em História, agora sob o vínculo de pesquisador colaborador sênior.

Ao longo de uma trajetória profissional que já se encontra na sua quinta década, Estevão Martins desenvolveu pesquisas de grande relevância. Participou, até agora, em universidades de todo o país, de inúmeras bancas de concurso para professor e de comissões examinadoras de trabalhos de mestrado, doutorado e livre-docência. Orientou mais de 70 mestres e doutores, além de cerca de 15 estágios de pós-doutoramento. Tem, assim, contribuído decisivamente para formar um número quantitativa e qualitativamente expressivo de quadros para instituições nacionais de pesquisa e ensino superior, em diversas áreas da História, da Filosofia e das Relações Internacionais. O interesse por temas de filosofia e história alemãs levou o nosso homenageado a realizar ele próprio cinco estágios de pósdoutoramento nas Universidades de Munique, Gratz, Bochum e no Instituto de Altos Estudos em Humanidades de Essen, tendo sido por duas ocasiões bolsista da Fundação Alexander von Humboldt.

Tem também ocupado funções de destaque no universo acadêmico nacional e internacional. Uma lista dessas atividades incluiria, entre muitas outras, as funções de secretário geral e vice-presidente da

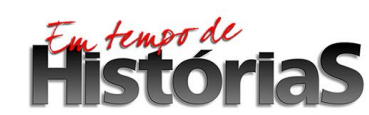


Comissão Internacional para a História das Instituições Representativas e Parlamentares; secretário da Associação Nacional de História; membro da direção da Comissão Internacional para a História e Teoria da Historiografia; presidente-fundador da Sociedade Brasileira de Teoria e História da Historiografia; membro do comitê assessor da área de História do CNPq. A presença em instituições e eventos internacionais e o intenso diálogo com especialistas estrangeiros nas suas áreas de atuação tornaram possível que ele desse uma significativa contribuição para a internacionalização das ciências humanas brasileiras. Os impactos dessa contribuição, diga-se de passagem, não se circunscrevem à Universidade de Brasília, pois abrangem várias outras instituições nacionais com cujos grupos de pesquisa ele mantém estreita cooperação. Importa, a esse respeito, mencionar a Universidade Federal do Paraná, a Universidade Federal de Goiás e, mais recentemente, Universidade Federal de Santa Maria.

$* * *$

O amplo trânsito e reconhecimento de que dispõe na comunidade acadêmica brasileira e internacional deve-se não só ao modo competente e comprometido como Estevão Martins desenvolve as mencionadas atividades. Ligam-se ainda mais fortemente ao impacto dos cerca de 200 itens bibliográficos por ele compostos, desde pelo menos 1975, quando publicou na, na hoje extinta revista Convivium, trabalho sobre a filosofia existencialista de Jean-Paul Sartre (Martins 1975).

O repertório bibliográfico do nosso homenageado foi inicialmente marcado por estudos de história das ideias centrados em Immanuel Kant. Na sua pesquisa doutoral, ele esforçou-se por entender a evolução do conceito de liberdade na obra do autor alemão. Concentrando-se na chamada fase ñprécríticaö isto é, naquele vasto momento que vai desde os primeiros escritos de Kant, datados do final da década de 1740, até a publicação da Crítica da razão pura, em 1881 (Röd 2008, 203-210) ï, Estevão Martins busca mapear os diálogos e as influências intelectuais que foram decisivas para a formação e maturação da ética kantiana (Martins 1976, iii). Na tese, e em alguns artigos que depois publicou em português (Martins 1978; Martins 1980; Martins 1983-a; Martins 1994), ele examina o percurso que levou Kant a ampliar progressivamente o conteúdo moral da sua concepção de liberdade. Partindo de um conceito fisicalista, herdado da tradição científica e da metafísica de Christian Wolf, Kant, segundo a tese de Martins, logrou transferir o conceito de liberdade para um plano robustamente moral. Fê-lo sob a influência da crítica de Christian August Crusius ao racionalismo de Wolf, por meio da adaptação crítica de elementos da teoria (não-racionalista) dos sentimentos morais desenvolvida 
pelos filósofos do Iluminismo escocês, bem como em diálogo com a obra de Jean-Jacques Rousseau (Martins 1976).

Ao longo dos anos 1980, Estevão Martins vai gradualmente acrescentando à competência de historiador da filosofia a de teórico da história. Nisso o ajudam temas e fundamentos que internalizou em meio ao estudo da filosofia natural, da teoria do conhecimento e da ética de Kant. É a partir desse substrato que vai, por exemplo, formular o apelo por uma ñteoria transcendental da históriaò (Martins 1979-a), ou examinar o ñuso de categoriasò entre os historiadores (Martins 1982). É também com ele que se aproxima da vanguarda da reflexão sobre história e historiografia produzida nos países de língua alemã no início da década de 1980 ï e em especial do teórico da história Jörn Rüsen e do filósofo das ciências sociais Karl Acham, os dois autores que mais fortemente o influenciarão durante a sua maturidade acadêmica. Interessante registro do estágio inicial dessa aproximação é a resenha, publicada ainda em 1983, a quatro volumes da importante coleção Contribuições para a teoria da história (Beiträge zur Historik), resultante das reuniões do grupo de trabalho que congregou os mais importantes nomes do campo na Alemanha e na Áustria, nos anos 1970 e 1980 (Martins 1983-b; ver também Martins 1992). ${ }^{2}$

É provável que Estevão Martins se tenha deixado atrair para a análise da historiografia a partir da intuição de que essa forma de conhecimento se estrutura sobre uma das mais elaboradas e enigmáticas combinações observáveis entre a razão pura e a razão prática. Em quase todos os seus trabalhos mais teóricos dos anos 1990 em diante é possível encontrar, com desenvolvimentos variáveis, um tema repleto de tensões, em que repercute aquele motivo kantiano fundamental. Trata-se do tema da compatibilização entre os caracteres metódicos garantidores de confiabilidade ao produto historiográfico e os atributos práticos com os quais esse produto se insere na dinâmica extraacadêmica da vida social. Desenvolvido a partir da dicotomia razão pura/razão prática, esse é um problema muito caro ao nosso emérito. Em busca de o resolver, ele muitas vezes pendulou entre a epistemologia, a metodologia, e a didática da história, num ir-e-vir que fermentou reflexões muito

\footnotetext{
${ }^{2}$ Os diálogos com as obras de Acham e Rüsen também ficam bem documentados, respectivamente, em Martins 1984 e Martins 1992. Estevão Martins buscou divulgar ideias dos seus principais interlocutores no campo da teoria da história também sob a forma de traduções, como em, por exemplo: Acham 1989, Acham 1992, Acham 2011, Meier 1997. Já destaquei, numa ocasião similar à que motivou o presente texto, o especial papel exercido por Estevão Martins na divulgação em língua portuguesa da teoria da história de Rüsen (Assis 2018, 270), nas condições de impulsionador de traduções, tradutor ou revisor de traduções de textos de autoria do teórico alemão - como em Rüsen 2001, Rüsen 2007-a, Rüsen 2007-b, e Rüsen 2015. Paralela, e possivelmente um pouco anterior, aos diálogos com Rüsen e Acham é a influência do filósofo da ciência austríaco Karl Popper, cuja obra é constantemente citada por Estevão Martins. O segundo chegou a traduzir um dos textos que compõem a coletânea Lógica das Ciências Sociais, reunida por Vamireh Chacon, com textos de autoria de Popper (1979).
}

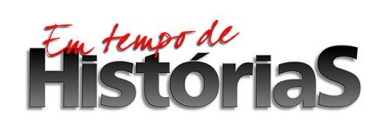


valiosas, como as que foram reunidas recentemente no livro Teoria e filosofia da história, uma coletânea de textos de cariz teórico publicados originalmente entre 2002 e 2016 (Martins 2017). ${ }^{3}$

Numa das mais expressivas contribuições agregada a esse livro, Estevão Martins (2017, 15-36) defende que o conhecimento histórico possui um caráter fundamentalmente ñrelacionalò posto que dependente de uma ñede fatorialò, isto é, de um enfeixamento de circunstâncias temporais, geográficas, sociais, culturais, psicológicas, entre outras, as quais formam o oposto do que quer que pudesse valer como um ponto de vista universal. Notam-se aqui (e, também, em muitos outros dos seus textos), por um lado, grandes concessões à tese da relatividade do conhecimento histórico, além de forte ênfase na dimensão pragmática do mesmo. Mas, por outro, Martins também sempre faz questão de observar a importância dos meios metódicos de controle intersubjetivo desenvolvidos na tradição da historiografia acadêmica, os quais equipara aos itens de um tácito ñcontrato social de qualidade historiográficaò (Martins 2017, 22). Segundo ele, ñão é por ser ó́elacionalôï e, por conseguinte, de certa forma relativo ï que o conhecimento perderia eventualmente sua qualidade científica ou sua fiabilidade. Esse risco existiria somente se houvesse abandono do controle metódico e intersubjetivo ou sacrifício da qualidade epistêmica em favor do arbítrio ficcional descomprometidoò (Martins 2017, 36). Martins costura assim um modelo de análise do conhecimento histórico que evita tanto o construtivismo quanto o relativismo, embora avance para bem além do realismo clássico, na direção do que define como ñrealismo mitigadoò ${ }^{4}$ Nesse modelo, a relatividade das circunstâncias de origem e destino das histórias convive dialeticamente com requisitos intersubjetivamente definidos de qualidade epistêmica ï em vez de simplesmente os anular.

\footnotetext{
${ }^{3}$ Para uma detalhada análise da obra, ver Mata 2019.

${ }^{4}$ Com essa expressão, por ele sempre repetida em aulas e palestras, Estevão Martins quer sinalizar o seu distanciamento em relação ao clássico pressuposto empirista de que a verdade seria a resultante de uma "correspondência rigorosa entre ocorrido, visto, pensado e enunciado" (Martins 2017, 39-40). A tese do realismo mitigado é bem detalhada na seguinte passagem: "Em que consiste, então, o realismo mitigado? Para o efeito de produção de um conhecimento histórico confiável, tem-se que o acesso à realidade é possível. Com isso, a atitude teórica pertinente é chamada de realismo. Por que mitigado? Pelo fato de o modo de ter acesso à realidade estar condicionado por pelo menos dois conjuntos circunstanciais: (a) a realidade com que o historiador lida é passada. Dessa forma, a circunstância em que o registro dessa realidade passada foi feito mitiga o realismo. (b) A realidade em que o historiador vive é presente. $O$ modo como o presente conforma o acesso do historiador à experiência imediata (vida atual) e à experiência mediata (vida passada) igualmente mitiga o realismo. A reflexão promovida pelo historiador sobre a experiência real dá-se, por conseguinte, de maneira mitigada, se se tomar a teoria clássica do realismo e de um acesso não mediado à 'realidade dos fatos'. Preservase, entretanto, a tese de que o historiador reflete sobre uma realidade a que tem acesso mediado pela percepção, que the permite produzir descrição, análise, entendimento, compreensão e explicação, por via de argumento discursivo na narrativa, da 'realidade' apreendida pela experiência imediata e/ou pela experiência medida pela pesquisa. $\mathrm{O}$ historiador move-se, por conseguinte, em um universo em que o tempo vivido e refletido enquadra a busca e a afirmação da verdade possível relativa a seu objeto" (Martins 2010-c, 8).
} 
Um dos recursos teóricos mais originais desenvolvidos por Estevão Martins é, aliás, a estratégia de abordar a atividade do historiador ï ou seja aquilo que Michel de Certeau (1982, 56-57), com grande sucesso, rebatizou como ñoperação historiográficaò ï nos quadros de uma teoria geral da ação racional. É natural que o agir humano pretérito ï os seus encadeamentos sincrônicos e diacrônicos, e os seus efeitos planejados e inesperados ï seja objeto privilegiado da atenção historiográfica. Mas os escritos teóricos de Estevão Martins lembram-nos sempre que ações não caracterizam apenas o polo objetivo do conhecimento histórico, pois no fim das contas também os historiadores são agentes e a historiografia, um modo de agir. $\mathrm{O}$ ato de escrever história é, portanto, ele próprio uma ação regida, no essencial, pela mesma lógica que caracteriza os fenômenos e processos do passado que os historiadores tomam por objeto de estudo. Lançando mão dessa apurada fenomenologia da ação, Martins atualiza de modo original a tradicional premissa hermenêutica de que uma ñconcordância originária prévia entre sujeito e objetoò (Humboldt 2010, 92) é uma condição necessária à compreensão histórica.

Deve-se acrescentar que duas importantes obras coletivas por ele organizadas foram, nas suas respectivas concepções, fortemente influenciadas por essa maneira de pensar teoricamente sobre a historiografia: Teoría e Metodología em la História de América Latina, volume co-organizado por Héctor Pérez Brignoli e publicado na Espanha (Martins; Brignoli 2006), no âmbito da coleção Historia General de América Latina, da Unesco; e A História Pensada, uma coletânea de traduções e de comentários a importantes textos oitocentistas sobre teoria e método históricos (Martins 2010-a).

$* * *$

A trajetória de Estevão Martins é marcada não só por contribuições acadêmicas, mas também por uma atuação institucional bastante abrangente. Nos anos 1980 e 1990, ele dividiu a sua atuação profissional entre as funções de professor da Universidade de Brasília e consultor legislativo do Senado Federal. Entre 1990 e 1992, chegou a chefiar, por dois anos a Secretaria de Assuntos Legislativos do Ministério da Justiça, e em 2003 também atuaria como coordenador-geral de cooperação internacional da CAPES. Toda essa experiência político-institucional orientou o seu interesse acadêmico por temas de história parlamentar, relações internacionais e direitos humanos, em torno dos quais gravita parte importante da sua obra, pelo menos desde meados dos anos 1990.

Cultura e poder, publicado em primeira edição em 2002, representa a sedimentação dessa orientação de pesquisa (Martins 2002). Nesse trabalho, Estevão Martins mobiliza o seu arsenal filosófico e a sua

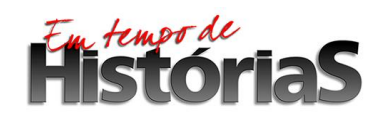


sensibilidade histórica para entender como e por que, das décadas finais do século 20 em diante, elementos culturais passam a se inserir decisivamente em dinâmicas de poder que outrora se supunham puramente políticas. A nova lógica da ação política que daí resulta é interpretada por ele em considerações muito penetrantes sobre a interação entre poder e identidade. Um dos objetivos centrais da obra é reafirmar a centralidade das ideias enquanto elementos impulsionadores da ação humana, à base dos quais se conformam as diferentes culturas.

Outro trabalho que representa essa orientação para temas de forte ressonância política é o livro Parcerias almejadas, publicado em 2012, que analisa o processo de integração da Europa, com foco em temas de política externa e segurança (Martins 2012). Esse trabalho desenvolve-se a partir de uma estruturação não-linear do ponto de vista cronológico: após detalhar o processo de construção institucional que levaria, de 1945 em diante, ao Mercado Comum Europeu e depois à União Europeia, Estevão Martins, na segunda metade do livro, surpreende o leitor com um recuo para o início do século 19, para re-perspectivar o processo da integração europeia num horizonte histórico de duração mais longa. Com isso, o livro pode ser lido não só como uma análise de diferentes momentos e configurações da política externa europeia, mas também como uma obra de síntese sobre a história contemporânea da Europa (ocidental). É um registro de como o nosso homenageado, para além de pensar teoricamente sobre a historiografia, também sabe vestir o figurino de historiador para produzir interpretações relevantes sobre fenômenos históricos substantivos. Em consonância com as premissas que orientam o seu pensamento teórico, trata-se de uma interpretação ñenfeixada nas circunstâncias do presenteò e dirigida por ideais de futuro, que incidem tanto sobre o espaço europeu como sobre o latinoamericano (e especialmente sobre o brasileiro). Estruturado desde uma perspectiva declaradamente eurotimista, o livro pretende, entre outras coisas, realçar a experiência da união econômica e política dos países europeus como elemento de orientação e inspiração para o movimento similar de integração sul-americana. ñA Europaòï resume ele ï ñé um projeto de vida dos europeus. E uma lição de coragem para outras regiões do mundo, inclusive para as que ainda engatinham, como o Mercosulò(Martins 2012, 25).

$* * *$

É, portanto, em três eixos que se pode agrupar a maior parte da obra de Estevão Martins: o da história da filosofia setecentista, centrado na figura de Kant; o da teoria, metodologia e didática da história; e por fim o da análise histórica e teórica de configurações políticas, instituições parlamentares e relações internacionais. Essa classificação aplica-se bem a quase todos os textos publicados por ele. Mas há

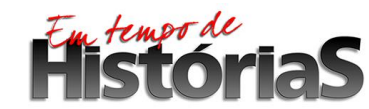


exceções importantes, como os trabalhos que escreveu sobre o filósofo tardo-medieval Nicolau de Cusa (Martins 2007); ou o artigo sobre a cafeicultura e os grupos de pressão em Campinas no final do século 19 (Martins 1979-b); ou ainda os seus estudos sobre o conceito moderno de revolução e os seus impactos no Brasil (Martins 1990-a; Martins 1990-b).

Os três eixos, juntamente com todas as suas exceções, são testemunhos inconfundíveis da amplitude dos interesses de pesquisa e da erudição do nosso homenageado. Mas classificações como essa não devem bloquear o nosso olhar para as grandes interfaces existentes entre as diferentes orientações investigativas seguidas por ele. Movendo-se constantemente nas fronteiras entre a filosofia, a história, a pedagogia, e as relações internacionais, ele soube encontrar meios originais para atualizar com sucesso uma qualidade que é sempre muito mais fácil de proclamar do que de praticar: a da interdisciplinaridade. Nessa busca incessante por situar as suas perspectivas de análise fora das zonas de conforto das disciplinas repousa, certamente, uma das contribuições mais importantes da sua obra (Araújo; Assis; Mata 2017, 9).

Em suma, Estevão de Rezende Martins é hoje um dos mais destacados representantes brasileiros de uma espécie de saber que se faz notar cada vez mais raramente: a ciência da mediação. Isso deriva não só da sua já aludida tendência para se colocar no espaço interseccional entre diferentes disciplinas, mas também do expressivo papel que tem desempenhado enquanto catalisador de diálogos entre as mesmas. Tal trabalho medianeiro revela ainda importantes consequências de caráter prático, que vão desde a promoção de intercâmbios acadêmicos entre o Brasil e outros países, e passam pela tantas vezes assumida missão de embaixador brasiliense junto a diferentes associações e instituições acadêmicas nacionais; pela solicitude com que serve de ponte entre o espaço universitário e diferentes esferas da organização institucional e burocrática do estado brasileiro; e pela já mencionada disposição para traduzir textos e disseminar ideias e autores que ficariam de outro modo menos acessíveis ao público leitor do espaço da língua portuguesa. Culminam, enfim, na constante generosidade com que se presta a intermediar conhecimentos e hábitos acadêmicos na condição de professor, algo de que se beneficiaram os milhares de estudantes que com ele estiveram em contato ao longo de mais de quatro décadas de exercício do magistério superior. Os principais favorecidos de tal atitude, quase nem é preciso dizê-lo, são os seus ex-orientandos, que na aprendizagem e no diálogo com ele desenvolveram ou adquiriram ferramentas decisivas às respectivas práticas de pesquisa e docência. ${ }^{5}$

5 Entre os ex-orientandos de Estevão Martins com atuação no ensino superior podem-se nomear, entre outros:
Adriana Iop Bellintani (UFRR); Aline Contti Castro (UFPB); Ana Carolina Barbosa Pereira (UFBA); Carlos Oiti 
Haveria ainda muito o que acrescentar a esse balanço sumário de realizações acadêmicas, mas o que acabou de ser dito já basta para justificar amplamente a cerimônia de hoje. Com o título de professor emérito, Estevão de Rezende Martins passa a figurar na memória da nossa instituição no mesmo patamar elevado onde estão personalidades como Alcida Rita Ramos, Aldo Paviani, Aliomar Baleeiro, Amado Cervo, Antônio Cançado Trindade, Athos Bulcão, Bárbara Freitag Rouanet, Carlos da Silva Veloso, Edson Nery da Fonseca, Eunice Soriano de Alencar, Emanoel Araújo, Flávio Rabelo Versiani, José Carlos Brandi Aleixo, Pedro Demo, Roque Laraia, Rubens Borba de Moraes, Vamireh Chacon, Victor Nunes Leal, entre outros. É, sem dúvida, um grupo muito distinto, do qual ele não poderia deixar de fazer parte.

Berbert Júnior (UFG); Christiane Marques Szesz (UEPG-PR); Eliesse dos Santos Teixeira Scaramal (UFG); Fábio Amaro da Silveira Duval (UFPEL-RS); Fábio Santiago Santa Cruz (UEG); Felipe Kern Moreira (FURG-RS); Gustavo da Frota Simões (UFRR); Luís Corrêa Lima (PUC-Rio); Luiz Sérgio Duarte da Silva (UFG); Marcos de Camargo von Zuben (UERN); Maria Carmem Côrtes Magalhães (UCB-DF); Maria Izabel Barboza de Morais Oliveira (UFMA); Renato Lopes Leite (UFPR); Simone Cristina Schmaltz de Rezende (PUC-GO); Tchella Fernandes Maso (UFGD); Walkíria Oliveira Silva (UFG; pós-doutoranda); além de mim próprio. A lista foi preparada de modo assistemático, mas é suficiente para indicar a inserção profissional e a dispersão geográfica dos ex-alunos mencionados.

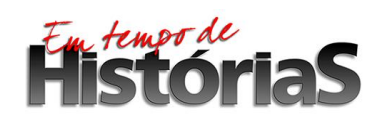




\section{Referências:}

Acham, Karl. ñConcepções do progresso na teoria social e na teoria da história. Uma investigação de história das idéiasò. Trad. Estevão de Rezende Martins. Leopoldianum, v. 16, n. 45 (1989), 23-42.

Acham, Karl. ñCiência social teórica e explicação histórica. Considerações metodológicasò Trad. Estevão de Rezende Martins. Síntese. Nova Fase, v. 19, n. 57 (1992), 179-197.

Acham, Karl. ñA compreensão histórica entre ceticismo e arbitrariedade: algumas considerações sobre as variantes recentes do relativismo histórico e culturalò. Trad. Estevão de Rezende Martins. História da Historiografia, n. 7 (2011), 201-224.

Araújo, Andre de Melo; Assis, Arthur Alfaix; Mata, Sérgio da. ñPrefácioò. In: A. Araújo; A. A. Assis; S. Mata (orgs.). Entre filosofia, história e relações internacionais: escritos em homenagem a Estevão de Rezende Martins (São Paulo: LiberArs, 2017), 9-12.

Assis, Arthur Alfaix. ñHistória, teoria e liberdade. Saudação a Jörn Rüsenò. Revista de Teoria da História, v. 20, n. 2 (2018), 266-273.

Certeau, Michel de. A escrita da história (Rio de Janeiro: Forense Universitária, 1982).

Humboldt, Wilhelm von. ñSobre a tarefa do historiadorò [1821]. In: Martins, Estevão (org.). A História Pensada. Teoria e Método da Historiografia Europeia do Século XIX: Teoria e Método na Historiografia Europeia do Século XIX. (São Paulo: Contexto, 2010), 82-100.

Martins, Estevão de Rezende. ñO argumento ontológico na introdução a ó Ser e o NadaÔde Jean-Paul Sartreò. Convivium, v. 14 (1975), 238-254.

Martins, Estevão de Rezende. Studien zu Kants Freiheitsauffassung in der vorkritischen Periode ï 1747-1770 (Augsburg: Blasaditsch, 1976).

Martins, Estevão de Rezende. ñAutonomia e liberdade. A influência de Rousseau sobre a ética précrítica de Kantò Revista Latinoamericana de Filosofia, v. 4 (1978), 99-117.

Martins, Estevão de Rezende. ñSentido e compreensão em História. Por uma teoria transcendental da históriaò Leopoldianum, v. 6, n. 12 (1979-a), 25-36. 
Martins, Estevão de Rezende. ñCafe et politique: groupes d'interet a Campinas (1880-1900). Revue Française dô̂Histoire dôOutre-Mer, v. 66, n.244/245 (1979-b), 421-433.

Martins, Estevão de Rezende. ñO caminho para a autonomia. Baumgarten e a concepção da liberdade no Kant pré-críticoò Revista Latinoamericana de Filosofia, v. 6, n. 2 (1980), 99-117.

Martins, Estevão de Rezende. ñO uso das categorias na ciência históricaò. Leopoldianum, v. 10, n. 20 (1982), 5-24.

Martins, Estevão de Rezende. ñO moralismo escocês do séc. XVIII e a concepção de liberdade no Kant pré-críticoò). Revista Portuguesa de Filosofia, t. 39, fasc. 3 (1983-a), 294-311.

Martins, Estevão de Rezende. ñAtualidade e relevância da teoria da históriaò. Revista da Sociedade Brasileira de Pesquisa Histórica, n. 1 (1983-b), 49-58.

Martins, Estevão de Rezende. ñO problema da objetividade nas ciências sociaisò Revista Brasileira de Filosofia, v. 34 (1984), 147-172.

Martins, Estevão de Rezende. ñLa revolution comme concept. Itineraire d'un probleme moderne. In: Michel Vovelle. (Org.). Lâmage de la Revolution Française (Paris: Pergamon, 1990-a), 1141-1148.

Martins, Estevão de Rezende. ñLa Révolution au Brésil: l'idée du nouveau et du définitfò. Cahiers des Amériques Latines, v. 10, (1990-b), 81-89.

Martins, Estevão de Rezende. ñConsciência histórica, prática e cultura: a propósito da teoria da história de Jörn Rüsenò Síntese. Nova Fase, v. 19, n. 56 (1992), 59-73.

Martins, Estevão de Rezende. ñCrusius e Kant. Crítica do racionalismoò. Revista Portuguesa de Filosofia, t. 50, fasc. 1/3 (1994), 253-260.

Martins, Estevão de Rezende. Relações internacionais: cultura e poder (Brasília: IPRI, 2002).

Martins, Estevão de Rezende; Brignoli, Héctor Pérez (orgs.). Teoría y metodología en la Historia de América Latina (Madri: Trotta, 2006) [Historia General de América Latina, vol. 9].

Martins, Estevão de Rezende. ñHistória e política no pensamento de Nicolau de Cusaò. In: Ernildo Stein. (Org.). A Cidade dos Homens e a Cidade de Deus (Porto Alegre: EST, 2007), 214-230. 
Martins, Estevão de Rezende (org.). A História Pensada. Teoria e Método da Historiografia Europeia do Século XIX: Teoria e Método na Historiografia Europeia do Século XIX (São Paulo: Contexto, 2010-a).

Martins, Estevão de Rezende. ñA culpa é de Hobbes e de Humeò [Entrevista a Ana Carolina Barbosa Pereira e Arthur Alfaix Assis]. História da Historiografia, n. 4 (2010-b), 390-405.

Martins, Estevão de Rezende. ñHistória: conhecimento, verdade, argumentoò. Dimensões, v. 24 (2010c), 5-32.

Martins, Estevão de Rezende. Parcerias Almejadas: Política externa, segurança, defesa e história na Europa (Belo Horizonte: Fino Traço, 2012).

Martins, Estevão de Rezende. Teoria e filosofia da história. Contribuições para o ensino de história (Curitiba: W.A., 2017).

Mata, Sérgio da. ñAnti-anti-iluminismo: a teoria da história segundo Estevão de Rezende Martinsò. ArtCultura, v. 21, n. 38 (2019), 199-205.

Meier, Christian. Política e graça. Trad. Estevão de Rezende Martins. (Brasília: Editora da Universidade de Brasília, 1997).

Popper, Karl. Lógica das ciências sociais. Trad. Estevão de Rezende Martins; Apio Cláudio Muniz Filho; Vilma de Oliveira Moraes e Silva (Rio de Janeiro: Tempo Brasileiro, 1979).

Röd, Wolfgang. O caminho da filosofia, v. 2: Do século XVII ao século XX. Trad. Maurício Cardozo; Caio Pereira; Roniere do Amaral (Brasília: Ed. UnB, 2008).

Rüsen, Jörn. Razão histórica: os fundamentos da ciência histórica (Brasília: Ed. UnB, 2001).

Rüsen, Jörn. Reconstrução do passado: os princípios da pesquisa histórica (Brasília: Ed. UnB, 2007a).

Rüsen, Jörn. História viva: formas e funções do conhecimento histórico (Brasília: Ed. UnB, 2007-b).

Rüsen, Jörn. Teoria da história. Uma teoria da história como ciência (Curitiba: Ed. UFPR, 2015).

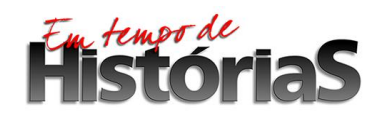


Saraiva, José Flávio Sombra. ñEstevão de Rezende Martins: um intelectual polivalenteò. In: A. Araújo; A. A. Assis; S. Mata (orgs.). Entre filosofia, história e relações internacionais: escritos em homenagem a Estevão de Rezende Martins. (São Paulo: LiberArs, 2017), 315-322.

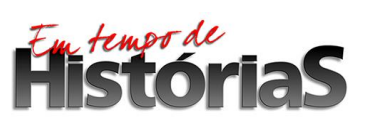

(PPGHIS/UnB) No. 34, Brasília, Jan - Jul 2019 ISSN 2316-1191 